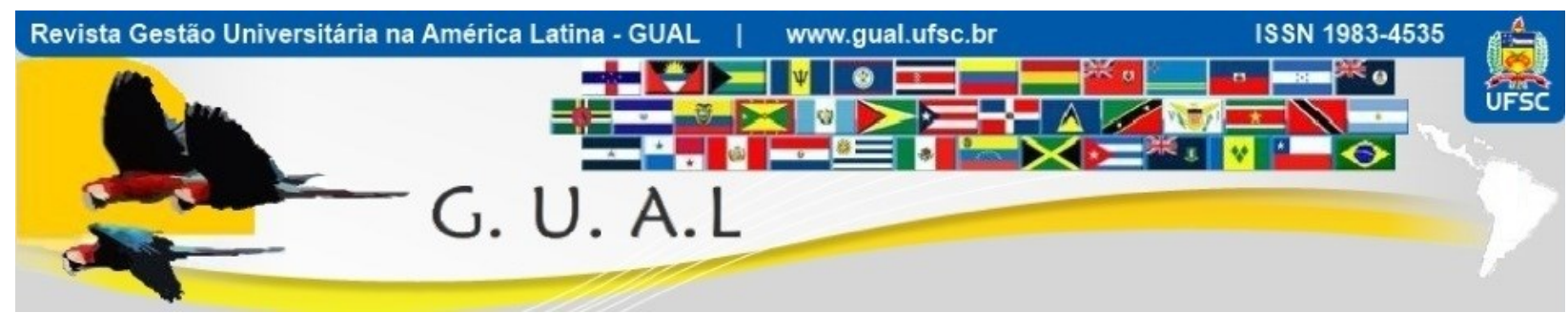

DOI: http://dx.doi.org/10.5007/1983-4535.2014v7n2p175

\title{
AVALIAÇÃO DOS CURSOS DO PROGRAMA NACIONAL DE FORMAÇÃO DE ADMINISTRAÇÃO PÚBLICA (PNAP): A VISÃO DOS DISCENTES DE UMA INSTITUIÇÃO FEDERAL DE ENSINO SUPERIOR
}

\author{
NATIONAL PUBLIC EDUCATION ADMINISTRATION PROGRAM (PNAP) \\ EVALUATION: A PUBLIC UNIVERSITY STUDENT'S VISION
}

\author{
Márcia Zampieri Grohmann, Doutora \\ Universidade Federal de Santa Maria - UFSM \\ marciazg@gmail.com \\ Luciana Aita Riss, Mestra \\ Centro Universitário Franciscano - UNIFA \\ lulu_riss@yahoo.com.br \\ Luciana Flores Battistella, Doutora \\ Universidade Federal de Santa Maria - UFSM \\ lutti@ufsm.br
}

Recebido em 26/outubro/2013

Aprovado em 25/abril/2014

Sistema de Avaliação: Double Blind Review

Esta obra está sob uma Licença Creative Commons Atribuição-Uso. 


\title{
RESUMO
}

O presente estudo tem por objetivos: conhecer os níveis de aceitação (mensurados pelas dimensões utilidade, facilidade, prazer, concentração, norma subjetiva e controle) e satisfação (mensuradas pelas dimensões confirmação das expectativas, atitude e satisfação) em relação aos cursos do Programa Nacional de Formação de Administração Pública (PNAP); conhecer o perfil dos alunos do PNAP em uma Instituição Federal de Ensino Superior (IFES) e verificar se o perfil dos respondentes interfere na aceitação do ensino a distância e com a satisfação e atitude frente aos cursos do PNAP. Para tanto, foi realizada uma pesquisa descritiva e quantitativa, pautada no modelo de Lee (2010), 236 alunos que posicionavam-se numa escala de 1 (discordo totalmente) a 7 (concordo totalmente). Os resultados apontaram boa avaliação em todas as dimensões, sendo que a menor média foi para a norma subjetiva $(4,88)$ e a dimensão melhor avaliada foi atitude $(6,14)$. Constatou-se, também, que houve influência do perfil em $16,96 \%$ das variáveis, fato que leva a concluir que o perfil do respondente interfere muito pouco nas percepções dos alunos sobre os cursos PNAP. Conclui-se que este é um estudo exploratório, porém contribui para a compreensão do ensino a distância por incluir novas dimensões aos estudos de utilização e aceitação de tecnologias no ensino, como confirmação de expectativas e satisfação.

Palavras-chave: Ensino a Distância. PNAP. Aceitação. Satisfação. Avaliação Discente.

\begin{abstract}
The present study aims to: meet the acceptance levels ( measured by the dimensions usefulness, ease , pleasure , concentration, subjective norm, and control) and satisfaction (measured by expectations confirmation, attitude and satisfaction ) in relation to the courses of the National Public Education Administration Program ( PNAP ) ; know the students profile in a Federal Institution of Higher Education ( IFES ) and verify if this profile interferes on acceptance and satisfaction about PNAP courses. So, was made a descriptive and quantitative research based on Lee (2010) model, with 236 students who asking whit a seven point scale (1- strongly disagree to 7- strongly agree). The results showed good rating in all dimensions, and the lowest average was for subjective norm (4.88) and the size was evaluated best attitude (6.14). It was found also that there was influence of profile $16.96 \%$ variable, which led to the conclusion that the profile of the respondent interferes very little in the perceptions of students on courses PNAP. We conclude that this is an exploratory study, but contributes to the understanding of distance education to include new dimensions to the study of the use and acceptance of technology in education like expectations confirmation and satisfaction.
\end{abstract}

Keywords: E-learning. PNAP. Acceptance. Satisfaction. Student Evaluation. 


\section{INTRODUÇÃO}

As Instituições de Ensino Superior (IES) encontram-se diante do desafio de se prepararem para a utilização da modalidade de Ensino a Distância (EaD). Frente a esta realidade, surgiu uma das principais políticas educacionais, dos últimos tempos, o projeto Universidade Aberta do Brasil (UAB) que se constitui em uma política de expansão quantitativa de vagas na rede pública de educação superior. Tal projeto visa o fornecimento de cursos superiores em polos situados em diversos municípios brasileiros.

A UAB possui atende diversos segmentos da sociedade, sendo que um deles é o Programa Nacional de Formação em Administração Pública (PNAP) que tem como objetivo a oferta de cursos em nível de graduação - bacharelado, e pós-graduação lato sensu especialização, destinados à criação de um perfil nacional do administrador público, propiciando a formação de gestores que utilizem uma linguagem comum e que compreendam as especificidades de cada uma das esferas públicas: municipal, estadual e federal.

No Brasil, constata-se que tem havido um aumento de publicações sobre ensino a distancia em importantes eventos científicos da área de administração. Porém, o número de trabalhos não acompanha a demanda, visto que, segundo o Censo de 2008 da Associação Brasileira de Educação a Distância (ABED), a área de administração está em segundo lugar, com 345 cursos ofertados a distância, no País.

Em relação aos estudos sobre UAB e PNAP, observa-se a existência de publicações com focos distintos como: política educacional do governo (SOUZA, 2012; DEMARCO, 2013), gestão dos cursos (ALVES, 2012; SILVA, ANDRADE, 2013; WEIDE, KICH, PERERIA, 2011), questões sobre a avaliação, qualidade dos cursos e perspectivas (JUSTEN, NETO, FELIPPE; 2012; TEIXEIRA, SILVA, OLIVEIRA; 2012; NETTO, OLIVEIRA, 2011), estudos sobre a função do tutor (GOMES, 2010; ISHIDA, STEFANO, ANDRADE, 2011; BATTISTI, et al, 2010), estudos sobre o perfil e evasão dos discentes UAB e PNAP (BRUNO-FARIA, FRANCO, 2011; ANDRADE, 2010), entre outros.

Porém, não foi encontrado nenhum estudo que relacione o perfil dos alunos, as questões de evasão, a aceitação do ensino a distância e a satisfação e aceitação com os cursos PNAP.

Frente a esta carência, o presente estudo tem por objetivos: conhecer os níveis de aceitação do ensino a distância (mensurados pelas dimensões utilidade, facilidade, prazer, 
concentração, norma subjetiva e controle) e satisfação em relação aos cursos PNAP (mensuradas pelas dimensões confirmação das expectativas, atitude e satisfação). Foram, também, criados os seguintes objetivos secundários: conhecer o perfil dos alunos do Programa Nacional de Formação de Administração Pública da Instituição Federal de Ensino Superior (IFES); compreender os motivos que levaram os alunos à evasão; verificar se o perfil dos respondentes interfere na aceitação do ensino a distância e com a satisfação e atitude frente aos cursos do PNAP.

Buscando responder aos objetivos propostos, foi realizada uma pesquisa descritiva, utilizando o Modelo de Aceitação de Ensino a Distância de Lee (2010), com alunos que evadiram, concluíram ou estão cursando os cursos do PNAP na IFES objeto deste estudo.

A estrutura do artigo apresenta um referencial sobre o ensino a distância, focando no modelo que foi utilizado na parte empírica do estudo (LEE, 2010), a seguir são apontadas informações sobre o Programa Nacional de Formação em Administração Pública (PNAP) e os cursos ofertados na IFES. Na sequencia é apresentado o método utilizado na pesquisa e os resultados encontrados, com analises e relações com outros estudos. Por fim, as conclusões do estudo retomam e respondem aos objetivos do trabalho, apresentam as limitações do estudo e sugestões para estudos futuros.

\section{REFERENCIAL TEÓRICO}

Para Langhi (1998) apud Vieira (2006), no século XX foi possível observar um movimento de expansão e consolidação do ensino a distância, notável pelo grande aumento de adesão da modalidade por instituições de ensino.

Alguns pesquisadores visualizam o ensino a distância como a aprendizagem baseada na web, que utiliza comunicação, colaboração, transferência de conhecimentos e treinamento baseados na web para agregar valores aos indivíduos e às organizações (PILLA, 2007). Embora seja geralmente aceita pela maioria dos pesquisadores que a aprendizagem pode ser entregue por qualquer dos meios eletrônicos que não sejam baseados em mídia na web, as tecnologias da web têm feito o ensino a distância ser mais amplamente utilizado por instituições acadêmicas bem como pelas organizações empresariais (HARASIM et al., 1998).

Apesar das divergências conceituais entre os pesquisadores, apontam-se algumas ideias que são unânimes entre os mesmos (NISKIER, 1999) como características do ensino a distância: separação entre professor- aluno; utilização de meios técnicos de comunicação; 


\section{AVALIAÇÃO DOS CURSOS DO PROGRAMA NACIONAL DE FORMAÇÃO DE ADMINISTRAÇÃO \\ PÚBLICA (PNAP): A VISÃO DOS DISCENTES DE UMA INSTITUIÇÃO FEDERAL DE ENSINO SUPERIOR \\ DOI: http://dx.doi.org/10.5007/1983-4535.2014v7n2p175}

organização de apoio-tutoria; Aprendizagem flexível; procedimentos Industriais, devido à produção e distribuição massiva.

A evolução do ensino a distância no Brasil é visível. Os números do censo da educação de 2008, no qual os dados foram coletados de 25/03/2009 a 12/06/2009, mostram que, só na graduação à distância, 115 instituições ofereceram 647 cursos em 2008. As matrículas na modalidade de ensino a distância aumentaram 96,9\% em relação ao ano anterior e, em 2008, passaram a representar $14,3 \%$ do total de matrículas no ensino superior. Além disso, o número de concluintes em EaD cresceu 135\% em 2008, se comparado a 2007. Dados do Ministério da Educação (MEC) apontam que, em 2010, já são quase três milhões de estudantes em EaD no Brasil, sendo grande a presença do setor privado. No entanto, segundo ele, a UAB, atualmente, já conta com mais de 45 Instituições de Ensino Superior (IES) integradas, tendo sido implantados 557 polos, com um total de 170 mil alunos de graduação e 80 mil em nível de especialização. A previsão era de atingir 600 mil estudantes em 2012.

No que se refere à literatura sobre as razões da adoção de tecnologias pelos indivíduos, esta é frequentemente descrita como uma área madura na literatura das ciências sociais aplicadas (VENKATESH, 2003). As pesquisas nessa área resultaram em uma série de modelos, com raízes em sistemas de informação, psicologia e sociologia, que normalmente explicam de $40 \%$ a $50 \%$ da variância da intenção do indivíduo em adotar a tecnologia. Os pesquisadores são confrontados com a escolha entre os modelos que focam na intenção de adoção de tecnologias, que investigam construtos externos ao indivíduo, como influência social (norma subjetiva), facilidade percebida de uso, e utilidade percebida (AJZEN, 1988; DAVIS, 1989), e modelos atitudinais, que investigam traços individuais e fatores psicológicos incentivadores e inibidores da adoção de determinada tecnologia (PARASURAMAN, 2000).

No estudo de Lee (2010), escolhido como referencial para este trabalho, o autor procurou, através da sintetização de cinco teorias (Modelo de Confirmação de Expectativas, Modelo de Aceitação de Tecnologia, Teoria do Comportamento Planeado, Teoria do Fluxo e Modelo de Pós-aceitação de Sistema de Informação), descobrir os fatores que influenciam a aceitação e intenção de usuários para continuar usando o ensino a distância.

Nesta pesquisa foi adotado o modelo de Lee (2010) adaptado, ou seja, por opção não será estudado o constructo intenção de continuidade dos alunos, visto que o objetivo deste trabalho consiste em compreender como funciona a aceitação dos alunos em relação ao ensino a distância, bem como diagnosticar a satisfação destes com os cursos PNAP. 


\section{AVALIAÇÃO DOS CURSOS DO PROGRAMA NACIONAL DE FORMAÇÃO DE ADMINISTRAÇÃO \\ PÚBLICA (PNAP): A VISÃO DOS DISCENTES DE UMA INSTITUIÇÃO FEDERAL DE ENSINO SUPERIOR \\ DOI: http://dx.doi.org/10.5007/1983-4535.2014v7n2p175}

Este modelo já havia sido traduzido e validado para o contexto nacional por Riss e Grohmann (2012), obtendo bons índices de confiabilidade e ajustes. A confiabilidade foi atestada pelos valores do Alpha de Cronbach superiores a 0,60 (utilidade - 0,83; facilidade0,84 ; atitude de uso- 0,87 ; diversão- 0,86 ; concentração- 0,87 ; norma subjetiva- 0,92 ; controle- 0,90; confirmação- 0,87; satisfação- 0,91). E a Análise Fatorial Confirmatória obteve índices satisfatórios de ajuste, para o modelo global (RMSEA $=0,07$; RMR $=0,18$; $\mathrm{NFI}=0,89, \mathrm{IFI}=0,94, \mathrm{TLI}=0,92, \mathrm{CFI}=0,93)$.

Cabe ressaltar que este estudo partiu de oito estudos iniciais que já buscaram identificar os fatores de aceitação e satisfação do ensino a distância, seja em ambientes de instituição de ensino ou corporativo. Dessa forma, trata-se de um modelo embasado em teorias consolidadas e testadas internacionalmente e que foi validado para o contexto nacional por Riss e Grohmann (2012).

Conforme o Ministério da Educação (2010), o Sistema Universidade Aberta do Brasil (UAB) sustenta-se em cinco eixos fundamentais: expansão pública da educação superior, considerando os processos de democratização e acesso; aperfeiçoamento dos processos de gestão das instituições de ensino superior, possibilitando sua expansão, em consonância com as propostas educacionais dos estados e municípios; avaliação da educação superior a distância, tendo por base os processos de flexibilização e regulação implantados pelo MEC; estímulo à investigação em educação superior a distância no País; financiamento dos processos de implantação, execução e formação de recursos humanos em educação superior a distância.

De acordo com a Capes (2010), com a supervisão da SEED/MEC e da CAPES, o Programa Nacional de Formação em Administração Pública (PNAP) tem como objetivo a oferta de cursos em nível de graduação - bacharelado, e pós-graduação lato sensu especialização, destinados à criação de um perfil nacional do administrador público, propiciando a formação de gestores que utilizem uma linguagem comum e que compreendam as especificidades de cada uma das esferas públicas: municipal, estadual e federal.

A IFES, na qual a pesquisa foi realizada, foi credenciada para atuar em Educação a Distância, tanto na graduação como na pós-graduação, por meio da Portaria ${ }^{\circ} 4.208$, de 17 de dezembro de 2004. A IFES, por meio da Coordenadoria de Educação a Distância, junto à PróReitoria de Graduação, procura organizar e implantar a política de EaD junto, especialmente, à comunidade regional e às outras instituições e órgãos municipais, estaduais, federais e 


\section{AVALIAÇÃO DOS CURSOS DO PROGRAMA NACIONAL DE FORMAÇÃO DE ADMINISTRAÇÃO \\ PÚBLICA (PNAP): A VISÃO DOS DISCENTES DE UMA INSTITUIÇÃO FEDERAL DE ENSINO SUPERIOR \\ DOI: http://dx.doi.org/10.5007/1983-4535.2014v7n2p175}

privados. A Universidade vem, portanto, construindo sua experiência e se ajustando à modalidade, dando-lhe identidade, calcada na realidade local e na trajetória da instituição e dos profissionais que atuam na EAD.

A UAB na IFES oferta oito cursos de graduação, oito de pós-graduação lato sensu e um de extensão para trinta e três Polos de Apoio Presencial nos Estados do Rio Grande do Sul, Paraná, São Paulo e Tocantins.

Em relação ao PNAP, são ofertados quatro cursos, sendo um de graduação e 3 de pósgraduação, cuja ofertas e números de vagas encontra-se sumarizados na Figura 1.

\begin{tabular}{|c|c|c|}
\hline Curso & Ano & Total de Vagas \\
\hline Bacharelado em Administração & 2010 & 240 \\
\hline \multirow[t]{2}{*}{ Especialização em Gestão Pública } & 2010 & 150 \\
\hline & 2011 & 200 \\
\hline \multirow{2}{*}{ Especialização em Gestão Pública Municipal } & 2010 & 100 \\
\hline & 2011 & 250 \\
\hline \multirow[t]{2}{*}{ Especialização em Gestão Pública de Organizações de saúde } & 2010 & 150 \\
\hline & 2011 & 250 \\
\hline Total & & 1.340 \\
\hline
\end{tabular}

Figura 1 Ofertas de vagas dos cursos do PNAP na IFES

\section{MÉTODO}

O presente estudo caracteriza-se por ser de natureza descritiva, de cunho quantitativo, uma vez que busca descrever a avaliação dos discentes do Programa Nacional de Formação em Administração Pública (PNAP) da IFES (natureza descritiva).

Foi utilizado o modelo adaptado de Lee (2010) para mensurar a aceitação do ensino a distância. Este modelo foi traduzido e validado para o contexto nacional por Riss e Grohmann (2012) e é formado por nove constructos (utilidade percebida, facilidade percebida, diversão, concentração, norma subjetiva, controle comportamental, confirmação, atitude de uso e satisfação), conforme aponta a Figura 2.

\begin{tabular}{|l|l|c|}
\hline \multicolumn{1}{|c|}{ Construtos } & \multicolumn{1}{c|}{ Definição } & Código \\
\hline Utilidade & Acrescimento que a pessoa acha obterá ao utilizar o EaD & PU1; PU2; PU3 \\
Facilidade & Esforço necessário para a utilização do EaD & F1; F2; F3 \\
Atitude & Motivação para fazer esforço para utilizar o EaD & A1; A2; A3 \\
Diversão & Prazer obtido ao utilizar o EaD & D1; D2; D3 \\
Concentração & Concentração necessária para utilizar o EaD & C1; C2; C3 \\
Norma Subjetiva & Pressão de outras pessoas para que se utilize o EaD & NS1; NS2; NS3 \\
Controle & Conhecimentos necessários para utilizar corretamente o EaD & CT1; CT2; CT3 \\
Confirmação & Confirmação em relação às expectativas prévias do EaD & CF1; CF2; CF3 \\
Satisfação & Satisfação do aluno em relação ao EaD & S1; S2 \\
\hline
\end{tabular}

Figura 2 Dimensões do modelo de avaliação do ensino a distância 


\section{AVALIAÇÃO DOS CURSOS DO PROGRAMA NACIONAL DE FORMAÇÃO DE ADMINISTRAÇÃO \\ PÚBLICA (PNAP): A VISÃO DOS DISCENTES DE UMA INSTITUIÇÃO FEDERAL DE ENSINO SUPERIOR \\ DOI: http://dx.doi.org/10.5007/1983-4535.2014v7n2p175}

Os dados foram coletados por meio de questionário divididos em duas partes: na primeira parte do questionário foram abordadas questões relacionadas ao perfil do respondente (gênero, faixa etária, idade e titulação, entre outras) e os motivos de evasão do curso (caso o respondente estivesse nessa situação); as questões relacionadas à aceitação da tecnologia encontram-se na segunda parte do questionário e as 27 variáveis foram mensuradas por escala tipo Likert de sete pontos com opções de resposta variando de "discordo fortemente" (1) para concordo plenamente (7).

Foi solicitada, junto às coordenações dos cursos do PNAP (Bacharelado em Administração, Especialização em Gestão Pública, Especialização em Gestão Pública Municipal e Especialização em Gestão Pública de Organizações de Saúde), a autorização para a aplicação da pesquisa, por e-mail, através do envio do projeto de dissertação, solicitando a listagem dos alunos, juntamente com os seus endereços eletrônicos. Dessa forma, a coleta de dados utilizou o método on-line (via internet), já que a maioria dos entrevistados reside em outras cidades.

A população para este estudo compreende o número de vagas ofertadas pelos cursos do PNAP em suas edições, totalizando 1.340 vagas, conforme a Figura 1. Procedeu-se com o cálculo da amostra para 95\% de confiança, chegando ao resultado de 400 respondentes. Foram enviados 487 questionários com o objetivo de obter uma margem de erro. Por fim, destaca-se que o percentual de retorno foi de 48,45\%, ou seja, 236 respondentes.

A análise dos dados seguiu as seguintes etapas: utilizaram-se os testes estatísticos univariados, através do cálculo de distribuições das frequências para averiguar o perfil da amostra pesquisada; foram realizados alguns testes estatísticos bivariados (teste $t$ para amostras independentes e ANOVA), para detectar as relações das variáveis caracterizadoras (demográficas e relacionadas ao curso dos respondentes) com as escalas de aceitação do ensino a distância e satisfação e atitude em relação aos cursos PNAP; por fim, foram calculadas as médias por dimensões e repetidos os testes de diferença de médias, para identificação das influências do perfil nas dimensões do modelo.

\section{RESULTADOS}

Os 236 estudantes que responderam esta pesquisa estão distribuídos nos quatro cursos do PNAP da seguinte forma: a maioria 44,5\% $(\mathrm{n}=105)$ cursou ou está cursando Especialização em Gestão pública; 29,2\% (n=69) participaram do curso de Especialização em 


\section{AVALIAÇÃO DOS CURSOS DO PROGRAMA NACIONAL DE FORMAÇÃO DE ADMINISTRAÇÃO \\ PÚBLICA (PNAP): A VISÃO DOS DISCENTES DE UMA INSTITUIÇÃO FEDERAL DE ENSINO SUPERIOR \\ DOI: http://dx.doi.org/10.5007/1983-4535.2014v7n2p175}

Gestão Pública Municipal; 25,4\% eram alunos da Graduação em Administração (n=60) e apenas $0,8 \%(n=2)$ do curso de Especialização em Gestão Pública e Organizações de Saúde.

A maior parte dos alunos, 55,9\% $(\mathrm{n}=132)$, está com o curso em andamento, $37,7 \%$ $(\mathrm{n}=89)$ já concluíram e 6,4\% $(\mathrm{n}=15)$ não concluíram seu respectivo curso. No que diz respeito ao gênero, pode-se perceber que a maioria dos participantes é do sexo feminino $(60,6 \%)$, os quais correspondem a 143 respondentes; enquanto apenas 93 dos respondentes é do sexo masculino, o que corresponde a 39,45\% dos alunos pesquisados. Este resultado vai ao encontro do censo da Associação Brasileira de Educação a Distância (Abed), que concluiu que $53,4 \%$ dos alunos dos cursos são do sexo feminino.

No que se refere à idade dos respondentes, 38,1\% possuem de 31 a 40 anos, representando 90 alunos; seguido de $36,4 \%$ de 21 a 30 anos, correspondendo a 86 alunos; 56 alunos possuem idade igual ou acima de 41 anos e o restante ( 3 alunos) situam-se na faixa etária de até 20 anos. Os resultados corroboram com o censo da Abed (2008), no qual 54\% do alunos que realizam cursos a distância no Brasil possuem mais de 30 anos. Ressalta-se que outra constatação da pesquisa foi que, no curso de graduação, predominam os jovens, enquanto que em cursos de especialização nota-se uma participação de estudantes de idade mais avançada e uma maior variação de idade.

Em relação à formação dos alunos, a maior parte $(39,8 \%$; $n=93)$ possui graduação em Administração, seguido de graduação em Ciências Contábeis (14\%; n=33) e graduação em Direito $(7,2 \% ; n=16)$, fato este que diz respeito aos alunos que se enquadram nos cursos de especialização. Ressalta-se que o perfil quanto a formação dos respondentes é bastante diferenciado, totalizando 22 cursos diferentes como: Letras, Pedagogia, Engenharia Agrícola, Geografia e Serviço Social, entre outros.

Para concluir, observou-se que a maioria dos respondentes são funcionários públicos (municipais, estaduais e federais), com um percentual de 54,24\% ( $\mathrm{n}=128)$ e $24,15 \%$ pretendem tornarem-se funcionários públicos.

Buscando identificar se algum dos cursos (Bacharelado em Administração, Especialização em Gestão Pública, Especialização em Gestão Pública Municipal e Especialização em Gestão Pública de Organizações de Saúde) apresentava um perfil de aluno próprio, foram realizados cruzamentos entre a variável curso e as demais variáveis demográficas (idade e sexo). Estes cruzamentos não apresentaram teste qui-quadrado significativo e, portanto, não foram encontradas diferenças no perfil dos alunos dos quatro 


\section{AVALIAÇÃO DOS CURSOS DO PROGRAMA NACIONAL DE FORMAÇÃO DE ADMINISTRAÇÃO \\ PÚBLICA (PNAP): A VISÃO DOS DISCENTES DE UMA INSTITUIÇÃO FEDERAL DE ENSINO SUPERIOR \\ DOI: http://dx.doi.org/10.5007/1983-4535.2014v7n2p175}

cursos analisados. Na sequência, foram realizados cruzamentos entre o perfil do estudante (idade, sexo) e o fato de ter concluído o curso. Constatou-se que a idade e o sexo não interferiram na desistência dos estudantes.

Foi disponibilizado aos alunos que abandonaram o curso um elenco de questões que poderiam representar a causa da desistência. O resultado demonstra que 93,6\% responderam que não continuaram, pois o curso não era o que eles esperavam, seguido da alegação de motivos pessoais e falta de tempo para realizar as tarefas. Alguns alunos citaram a falha na comunicação ou a demora na resposta de professores e tutores como fator que influenciou na desistência. Os estudos de Andrade (2010) e Bruno-Faria e Franco (2011) encontraram resultados semelhantes para a evasão dos alunos. Parece que um ponto fundamental para o sucesso de tal prática educativa é a interação tutor aluno, conforme apontam Batistti, et al (2010) e Gomes (2010).

Os próximos resultados visam atender ao objetivo central da pesquisa que é o de conhecer os níveis de aceitação do ensino a distância (mensurados pelas dimensões utilidade, facilidade, prazer, concentração, norma subjetiva e controle) e satisfação em relação aos cursos PNAP (mensuradas pelas dimensões confirmação das expectativas, atitude e satisfação). A Tabela 1 apresenta a média e desvio-padrão de todas as respostas das variáveis que compõem o modelo de avaliação do ensino a distância nos cursos PNAP.

Tabela 1 Avaliação do ensino a distância nos cursos PNAP

\begin{tabular}{|c|c|c|}
\hline Variáveis & Média & Desvio \\
\hline \multicolumn{3}{|l|}{ Utilidade Percebida } \\
\hline PU1- Usar o ensino a distância pode melhorar meu desempenho no aprendizado & 5,66 & 1,23 \\
\hline PU2- Usar o ensino a distância pode melhorar a eficiência de meu aprendizado & 5,59 & 1,25 \\
\hline PU3- Eu considero que ensino a distância é útil para mim & 6,30 & 0,91 \\
\hline \multicolumn{3}{|l|}{ Facilidade Percebida } \\
\hline F1- Aprender a utilizar o sistema de ensino a distância é fácil para mim & 6,23 & 0,98 \\
\hline F2- É fácil adquirir as habilidades para usar o sistema de ensino a distância & 6,07 & 0,99 \\
\hline F3- Em geral, o sistema de ensino a distância é fácil de usar & 6,08 & 0,97 \\
\hline \multicolumn{3}{|l|}{ Diversão Percebida } \\
\hline D1- Usar o ensino a distância é prazeroso & 5,50 & 1,37 \\
\hline D2- É divertido usar o ensino a distância & 5,04 & 1,62 \\
\hline D3- É interessante usar o ensino a distância & 6,03 & 1,06 \\
\hline \multicolumn{3}{|l|}{ Concentração Necessária } \\
\hline C1- O site do ensino a distância fornece os serviços que eu preciso & 5,56 & 1,16 \\
\hline C2- Eu me sinto confortável em usar as funções e os serviços do site de ensino a distância & 5,80 & 1,04 \\
\hline C3- O site do ensino a distância fornece informações completas & 5,45 & 1,23 \\
\hline C4- O site do ensino a distância fornece informações fáceis de compreender & 5,57 & 1,17 \\
\hline \multicolumn{3}{|l|}{ Norma Subjetiva } \\
\hline NS1- Pessoas importantes para mim me incentivam a usar o ensino a distância & 4,95 & 1,58 \\
\hline NS2- Pessoas que me influenciam acham que eu devo usar o ensino a distância & 4,77 & 1,63 \\
\hline
\end{tabular}




\section{AVALIAÇÃO DOS CURSOS DO PROGRAMA NACIONAL DE FORMAÇÃO DE ADMINISTRAÇÃO PÚBLICA (PNAP): A VISÃO DOS DISCENTES DE UMA INSTITUIÇÃO FEDERAL DE ENSINO SUPERIOR \\ DOI: http://dx.doi.org/10.5007/1983-4535.2014v7n2p175}

NS3- Pessoas que eu valorizo a opinião acham que eu devo usar o ensino a distância

\begin{tabular}{|c|c|c|}
\hline NS3-Pessoas que e & 4,94 & 1,59 \\
\hline \multicolumn{3}{|l|}{ Controle Percebido } \\
\hline CT1- Eu tinha total controle em utilizar o sistema de ensino a distância & 5,37 & 1,40 \\
\hline CT2- Eu possuía os recursos, conhecimentos e habilidades para usar o ensino a distância & 5,45 & 1,34 \\
\hline $\begin{array}{l}\text { CT3- Eu teria habilidade para usar bem o ensino a distância nos meus processos de } \\
\text { aprendizagem }\end{array}$ & 5,55 & 1,32 \\
\hline \multicolumn{3}{|l|}{ Confirmação das Expectativas } \\
\hline $\begin{array}{l}\text { CF1- Minha experiência em utilizar o sistema de ensino a distância foi melhor do que eu } \\
\text { esperava }\end{array}$ & 5,73 & 1,30 \\
\hline $\begin{array}{l}\text { CF2- O nível de serviço oferecido pelo sistema de ensino a distância foi melhor do que eu } \\
\text { esperava }\end{array}$ & 5,23 & 1,52 \\
\hline CF3- O sistema de ensino a distância satisfez minhas demandas mais do que eu precisava & 5,02 & 1,60 \\
\hline \multicolumn{3}{|l|}{ Atitude em Relação ao Curso } \\
\hline A1- Usar o ensino a distância é uma boa ideia & 6,31 & 0,85 \\
\hline A2- Eu gosto de usar o ensino a distância & 6,09 & 1,10 \\
\hline A3- Eu desejo utilizar o ensino a distância & 6,03 & 1,27 \\
\hline \multicolumn{3}{|l|}{ Satisfação com o Curso } \\
\hline S1 - Estou satisfeito com o desempenho do ensino a distância & 5,44 & 1,51 \\
\hline S2- Estou satisfeito com a experiência de usar o ensino a distância & 5,73 & 1,41 \\
\hline
\end{tabular}

Conforme Nunnally (1975), é adequado utilizar-se da média da escala (de 1 a 7) para determinar altos ou baixos níveis, sendo que as médias acima de 4 identificam um nível superior ao desejado para a respectiva variável. Neste estudo, a escala varia (de 1 a 7), sendo que os valores 1 e 2 eram para grande discordância; 2 e 3 para discordância média; 4 e 5 para concordância média e 6 e 7 para grande concordância. Com base nos resultados, pôde-se observar que os entrevistados possuem um grau de concordância alta, já que a média de um modo geral variou entre 4 e 6 .

De modo geral, nenhuma média foi inferior a 3,50. As variáveis com maior média apresentaram um desvio-padrão considerado baixo, indicando que existe pequena dispersão nas respostas dadas pelos participantes, conforme Tabela 8. Observa-se que as variáveis que apresentaram maior média foram: A1 - usar o ensino a distância é uma boa ideia, que faz parte do constructo atitude com média 6,31 e menor desvio-padrão do modelo no valor de 0,85, interpretando-se assim que usar o ensino a distância é uma boa ideia. Vale ressaltar que, conforme a Teoria da Ação Racional (TRA), o comportamento de uma pessoa é determinado conjuntamente pela atitude da pessoa e norma subjetiva sobre o comportamento em questão. A variável PU3, que integra o constructo percepção de utilidade, apresentou média de 6,30 e desvio-padrão de 0,91, indicando que as pessoas consideram o ensino a distância útil, corroborando com o estudo de Selim (2003).

Em seguinte tem-se a variável F1, a qual apresentou média de 6,23 e desvio-padrão de 0,98, demonstrando que as pessoas têm facilidade em utilizar o ensino a distância, aspecto 
também abordado no estudo de Selim (2003) como fator determinante para a aceitação do ensino a distância. Já a variável D3 do constructo diversão, com média de 6,03 e desvio de 1,06, refere que os participantes acham interessante utilizar o ensino a distância. Com relação ao constructo concentração, a variável $\mathrm{C} 2$, com média 5,80 e desvio de 1,04 , refere que as pessoas se sentem confortáveis a usar as funções e serviços do site de ensino a distância. A variável NS1, que está ligada à Norma Subjetiva, com média de 4,95 e desvio de 1,58, demonstra que as pessoas consideradas importantes para os sujeitos pesquisados incentivam os mesmos a utilizar o ensino a distancia.

As variáveis CT3 e CF1, ligadas ao controle comportamental percebido e à confirmação, respectivamente, tiveram médias de 5,55 e 5,73, seguidas de desvio-padrão de 1,32 e 1,30, demonstrando que a experiência de utilizar o ensino a distância foi melhor do que eles esperavam, superando, então, suas expectativas, bem como consideram que teria habilidade suficiente para utilizar o ensino a distância em seus processos de aprendizagem.

No que se refere ao constructo satisfação, a variável S2 apresentou a maior média, de 5,73 e desvio de 1,41, demonstrando que as pessoas estão satisfeitas com a experiência em utilizar o ensino a distância.

Visando compreender, de uma forma mais ampla, a avaliação dos alunos sobre os cursos do PNAP de ensino a distância, foram realizadas análises em relações às dimensões do modelo utilizado (Figura 3). Para tanto, utilizou-se o procedimento estatístico de transformação das variáveis em uma única variável, pelo cálculo da média das médias.

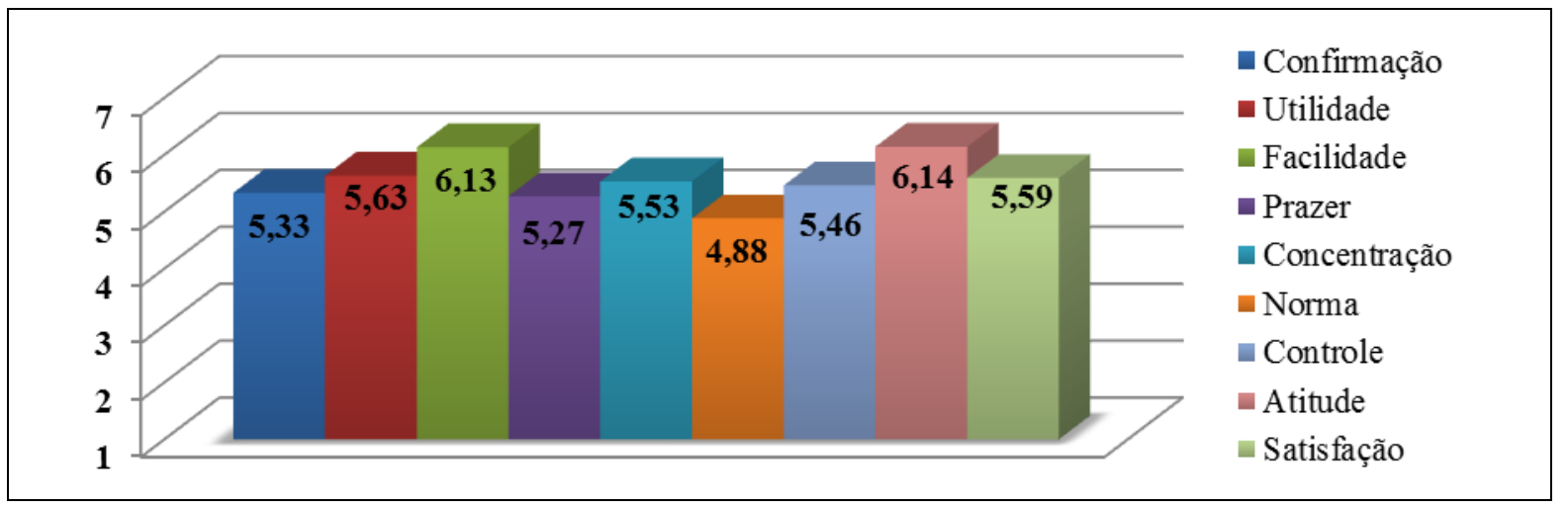

Figura 3 Médias das dimensões

Destaca-se, novamente, que a escala de 7 pontos possuía como 4 seu ponto neutro. Como todas as dimensões obtiveram médias superiores a 4 , observa-se que as avaliações 
foram positivas. Para uma melhor avaliação dessas médias, utilizou-se o parâmetro: 7 ótimo; 6 - bom; 5- moderadamente bom; 4 - neutro.

A norma subjetiva identifica a pressão de outras pessoas para que o aluno utilizasse o ensino a distância e os resultados apontaram média de 4,88 (desvio-padrão = 1,50). Isso demonstra que os alunos foram moderadamente influenciados por outras pessoas para fazerem um dos cursos do PNAP. O prazer obtido em realizar um dos cursos do PNAP foi classificado como razoavelmente bom, com uma média de 5,27 (desvio-padrão=1,42). A confirmação das expectativas em relação ao curso do PNAP obteve média de 5,33 (desvio-padrão = 1,32), ou seja, classificada como moderadamente boa. Em relação aos conhecimentos necessários para utilizar corretamente as ferramentas do curso de ensino a distância, os alunos apontaram uma média de 5,46, classificando o controle como moderadamente bom (desvio-padrão $=1,24)$. A dimensão que analisava o nível de concentração necessária para realizar um dos cursos do PNAP também obteve avaliação moderadamente alta, com média de 5,53 (desvio-padrão = $1,04)$, identificando que os alunos não necessitavam de muita concentração para a realização do curso.

O grau de satisfação dos alunos com o curso do PNAP foi moderadamente bom, com média de 5,59 (desvio-padrão de 1,40). Média bem similar $(5,63)$ foi obtida na dimensão de utilidade do curso PNAP, um valor considerado alto para cursos desta natureza mas que pode ter sido altamente influenciado pelo fato de que grande parte dos alunos do curso são funcionários públicos que obterão aumento salarial com a obtenção de um título de pósgraduação.

As dimensões com melhor avaliação foram facilidade e atitude. A avaliação média dos alunos em relação ao esforço necessário para utilização do ensino a distância foi de 6,13 (desvio-padrão $=0,86$ ), identificando que o grau de facilidade do sistema de ensino a distância é alto. Por fim, a motivação para fazer esforço em fazer em dos cursos do PNAN foi a dimensão com maior média $(6,14)$, provavelmente pelo fato do curso ser percebido pelos alunos como uma forma acessível de crescimento pessoal e profissional.

Em termos de concordância ou divergência de opiniões, destaca-se que a dimensão com maior concordância de opiniões (menor desvio padrão) foi a facilidade em utilizar o sistema do ensino a distância (desvio-padrão de 0,86) e a maior divergência foi na dimensão prazer percebido (desvio-padrão de 1,42). 
Buscando responder um dos objetivos deste estudo: identificar se existe influência do perfil dos alunos na aceitação do ensino a distância, foram feitos cruzamentos das variáveis do modelo de aceitação de tecnologia com o perfil dos alunos, considerando os seguintes aspectos: sexo, idade, curso, fase do curso e ocupação. Ressalta-se que os resultados do cruzamento das variáveis com o sexo dos respondentes não apresentou significância, não sendo, portanto, aqui apresentado. Este resultado não vem ao encontro do estudo de Venkatesh e Morris (2000), porém no estudo de Gefen e Straub (1997) este fato ocorreu. Outra variável do perfil que não impactou na avaliação das variáveis do modelo foi a ocupação dos respondentes.

Observa-se, através da Tabela 2, que algumas variáveis apresentaram diferenças significativas com relação às idades. Para a realização destes testes foi feito o agrupamento entre a faixa etária até 20 anos, por apresentar apenas 3 respondentes, com a faixa etária de até 30 anos. O teste ANOVA, para análise de diferença de médias, demonstrou que houve diferenças estatisticamente significativas para as três variáveis da dimensão controle percebido.

Na variável CT1 - eu tinha total controle em utilizar o sistema de ensino a distância $(\mathrm{F}=2,933$ e sig= 0,054), observa-se que as médias para esta variável foram diminuindo com o aumento da idade, ou seja, pode-se afirmar que quanto mais jovens o aluno for, maior é seu controle em relação ao sistema (moodle) usado para o ensino a distância.

Comportamento similar ocorreu com a variável CT2 - Eu possuía os recursos, conhecimentos e habilidades para usar o ensino a distância $(\mathrm{F}=3,458$ e sig - 0,033), cujas maiores médias foram entre os alunos até 30 anos (média de 5,71) e as menores médias entre os alunos com mais de 40 anos (média de 5,12).

Por fim, também foi constatado diferenças na variável CT3 - Eu teria habilidade para usar bem o ensino a distância nos meus processos de aprendizagem $(\mathrm{F}=3,022$ e sig=0,051). As médias entre as faixas etárias de 31 a 40 anos (média de 5,52) e dos respondentes com mais de 40 anos (média de 5,57) foram muito próximas, porém, os alunos mais novos apresentaram maior controle em relação a possuir as habilidades necessárias para utilizar o ensino a distâncias nos processos de aprendizagem. As demais variáveis não apresentaram significância entre idade e aceitação do ensino a distância. 


\section{AVALIAÇÃO DOS CURSOS DO PROGRAMA NACIONAL DE FORMAÇÃO DE ADMINISTRAÇÃO \\ PÚBLICA (PNAP): A VISÃO DOS DISCENTES DE UMA INSTITUIÇÃO FEDERAL DE ENSINO SUPERIOR \\ DOI: http://dx.doi.org/10.5007/1983-4535.2014v7n2p175}

Tabela 2 Influência da idade na aceitação do ensino a distância

\begin{tabular}{|c|c|c|c|c|}
\hline Variável & Idade & Média & $F$ & Sig \\
\hline \multirow{3}{*}{$\begin{array}{l}\text { CT1- Eu tinha total controle em utilizar o } \\
\text { sistema de ensino a distância }\end{array}$} & Até 30 anos & 5,56 & \multirow[t]{3}{*}{2,933} & \multirow[t]{3}{*}{0,054} \\
\hline & 31 a 40 anos & 5,48 & & \\
\hline & Mais de 40 anos & 5,02 & & \\
\hline \multirow{3}{*}{$\begin{array}{l}\text { CT2- Eu possuía os recursos, conhecimentos e } \\
\text { habilidades para usar o ensino a distância }\end{array}$} & Até 30 anos & 5,71 & \multirow[t]{3}{*}{3,458} & \multirow[t]{3}{*}{0,033} \\
\hline & 31 a 40 anos & 5,47 & & \\
\hline & Mais de 40 anos & 5,12 & & \\
\hline \multirow{3}{*}{$\begin{array}{l}\text { CT3- Eu teria habilidade para usar bem o } \\
\text { ensino a distância nos meus processos de } \\
\text { aprendizagem }\end{array}$} & Até 30 anos & 5,81 & \multirow[t]{3}{*}{3,022} & \multirow[t]{3}{*}{0,051} \\
\hline & 31 a 40 anos & 5,52 & & \\
\hline & Mais de 40 anos & 5,57 & & \\
\hline
\end{tabular}

Identifica-se, na Tabela 3, que as variáveis que apresentaram diferenças significativas na relação entre curso e aceitação do ensino a distância foram PU3, D1, NS1, NS2, CF1, CF3 e S2. Para realização desta análise de dados, optou-se por excluir os alunos do curso de Gestão Pública de Organizações de Saúde, pois havia apenas dois respondentes, numero muito pequeno para representar a opinião de alunos deste curso. Além disso, não é estatisticamente adequado que se compare grupos de tamanhos muito diferentes.

$\mathrm{Na}$ dimensão diversão, houve diferença na variável D1 - usar o ensino a distância é prazeroso $(\mathrm{F}=5,877$, sig= 0,003), na qual percebe-se, através das médias, que os alunos do de graduação em Administração (média=6,01) possuem médias maiores e, portanto, acham mais prazeroso usar o ensino a distância do que os alunos dos cursos de Gestão Pública (média=5,35) e Gestão Pública Municipal (média=5,29).

Outras variáveis que foram significativas são integrantes da dimensão norma subjetiva: NS1 $(F=4,684$, sig=0,010) e NS2 $(F=4,336$, sig. $=0,014)$. Verificou-se que o mesmo comportamento é encontrado em ambas variáveis, com médias superiores para os alunos do curso de graduação em Administração. Em relação à variável NS1, ou seja, os alunos do curso de graduação em Administração (média=5,47) afirmam que valorizam e levam em conta a opinião de pessoas importantes (são influenciadas) no momento de tomar uma atitude ou decisão, como neste caso, a utilização do ensino a distância, do que os alunos dos cursos de especialização em GP (média=4,69) e especialização em GPM (média=4,98). No que tange à variável NS2, os alunos do curso de graduação em Administração apresentaram maior média $(5,32)$ para a afirmação de que "pessoas que me influenciam acham que eu devo usar o ensino a distância", seguidos pelos alunos do curso de especialização em GP (média=4,50) e especialização em GPM (média=4,77). 


\section{AVALIAÇÃO DOS CURSOS DO PROGRAMA NACIONAL DE FORMAÇÃO DE ADMINISTRAÇÃO PÚBLICA (PNAP): A VISÃO DOS DISCENTES DE UMA INSTITUIÇÃO FEDERAL DE ENSINO SUPERIOR DOI: http://dx.doi.org/10.5007/1983-4535.2014v7n2p175}

Tabela 3 Influência do curso escolhido e aceitação do ensino a distância

\begin{tabular}{|c|c|c|c|c|}
\hline Variável & Curso & Média & $\bar{F}$ & Sig \\
\hline \multirow[t]{3}{*}{ D1- Usar o ensino a distância é prazeroso } & Graduação em ADM & 6,01 & \multirow[t]{3}{*}{5,877} & \multirow[t]{3}{*}{0,003} \\
\hline & Especialização em GP & 5,35 & & \\
\hline & Especialização em GPM & 5,29 & & \\
\hline \multirow{3}{*}{$\begin{array}{l}\text { NS1- Pessoas importantes para mim me } \\
\text { incentivam a usar o ensino a distância }\end{array}$} & Graduação em ADM & 5,47 & \multirow[t]{3}{*}{4,684} & \multirow[t]{3}{*}{0,010} \\
\hline & Especialização em GP & 4,69 & & \\
\hline & Especialização em GPM & 4,98 & & \\
\hline \multirow{3}{*}{$\begin{array}{l}\text { NS2- Pessoas que me influenciam acham que } \\
\text { eu devo usar o ensino a distância }\end{array}$} & Graduação em ADM & 5,32 & \multirow[t]{3}{*}{4,336} & \multirow[t]{3}{*}{0,014} \\
\hline & Especialização em GP & 4,50 & & \\
\hline & Especialização em GPM & 4,77 & & \\
\hline \multirow{3}{*}{$\begin{array}{l}\text { CF1- Minha experiência em utilizar o sistema } \\
\text { de ensino a distância foi melhor do que eu } \\
\text { esperava }\end{array}$} & Graduação em ADM & 6,21 & \multirow[t]{3}{*}{5,655} & \multirow[t]{3}{*}{0,004} \\
\hline & Especialização em GP & 5,61 & & \\
\hline & Especialização em GPM & 5,51 & & \\
\hline \multirow{3}{*}{$\begin{array}{l}\text { CF3- O sistema de ensino a distância satisfez } \\
\text { minhas demandas mais do que eu precisava }\end{array}$} & Graduação em ADM & 5,52 & \multirow[t]{3}{*}{3,333} & \multirow[t]{3}{*}{0,037} \\
\hline & Especialização em GP & 4,86 & & \\
\hline & Especialização em GPM & 4,86 & & \\
\hline \multirow{3}{*}{$\begin{array}{l}\text { PU3 - Eu considero que ensino a distância é } \\
\text { útil para mim }\end{array}$} & Graduação em ADM & 6,55 & \multirow[t]{3}{*}{3.447} & \multirow[t]{3}{*}{0,033} \\
\hline & Especialização em GP & 6,17 & & \\
\hline & Especialização em GPM & 6,29 & & \\
\hline \multirow{3}{*}{$\begin{array}{l}\text { S2- Estou satisfeito com a experiência } \\
\text { de usar o ensino a distância }\end{array}$} & Graduação em ADM & 6,18 & \multirow[t]{3}{*}{3,956} & \multirow[t]{3}{*}{0,020} \\
\hline & Especialização em GP & 5,56 & & \\
\hline & Especialização em GPM & 5,61 & & \\
\hline
\end{tabular}

Já no que se refere ao construto confirmação, a questão CF1 - minha experiência em utilizar o sistema de ensino a distância foi melhor do que eu esperava $(F=5,655$ e sig. $=0,004)$ apresentou médias superiores nos alunos do curso de graduação em Administração (média $=6,21$ ), demonstrando que, para eles, a experiência em utilizar o sistema de ensino a distância foi melhor do que eles esperavam. Com relação a variável, CF3 - o sistema de ensino a distância satisfez as minhas demandas mais do que eu precisava $(\mathrm{F}=3,333$ e sig= 0,037), pode-se afirmar que os alunos que mais tiveram satisfação acima do esperado foram os da graduação em Administração (média=5,52), seguidos pelos alunos dos dois cursos de especialização, que apresentaram as mesmas médias para esta variável (média=4,86).

A variável PU3 - Eu considero que ensino a distância é útil para mim -, da dimensão utilidade percebida, apresentou diferenças nas opiniões dos respondentes $(\mathrm{F}=3,447$; sig=0,033). Os alunos do curso de graduação em Administração foram os que visualizaram a maior utilidade do curso (média=6,55), seguidos dos alunos da especialização em GPM (média de 6,29) e, com menores médias, ficou o grupo de alunos da especialização em GP (média=6,17).

Na dimensão satisfação, a variável S2 - estou satisfeito com a experiência do ensino a distância $(F=3,956$, sig. $=0,020)$, demonstrou que os alunos dos cursos de graduação em 


\section{AVALIAÇÃO DOS CURSOS DO PROGRAMA NACIONAL DE FORMAÇÃO DE ADMINISTRAÇÃO \\ PÚBLICA (PNAP): A VISÃO DOS DISCENTES DE UMA INSTITUIÇÃO FEDERAL DE ENSINO \\ SUPERIOR \\ DOI: http://dx.doi.org/10.5007/1983-4535.2014v7n2p175}

administração (média=6,18) são os mais satisfeitos e que os menos satisfeitos são os alunos da especialização em GP (média= 5,56).

Os respondentes foram indagados em que fase do curso estavam, devendo optar por uma das alternativas: concluído, não concluído ou em andamento. Desta forma, procurou-se, através da análise da variância, verificar qual variável apresenta significância na fase do curso que o aluno se encontra, de acordo com a Tabela 4.

Tabela 4 Influência da fase do curso na aceitação do ensino a distância

\begin{tabular}{|c|c|c|c|c|}
\hline Variável & Fase do curso & Média & $\bar{F}$ & Sig \\
\hline $\begin{array}{l}\text { PU1- Usar o ensino a distância pode melhorar meu } \\
\text { desempenho no aprendizado }\end{array}$ & $\begin{array}{l}\text { Concluído } \\
\text { Não Concluído } \\
\text { Em andamento }\end{array}$ & $\begin{array}{l}5,90 \\
5,07 \\
5,57\end{array}$ & 3,696 & 0,026 \\
\hline A1- Usar o ensino a distância é uma boa ideia & $\begin{array}{l}\text { Concluído } \\
\text { Não Concluído } \\
\text { Em andamento }\end{array}$ & $\begin{array}{l}6,46 \\
5,64 \\
6,29\end{array}$ & 5,951 & 0,003 \\
\hline A2- Eu gosto de usar o ensino a distância & $\begin{array}{l}\text { Concluído } \\
\text { Não Concluído } \\
\text { Em andamento }\end{array}$ & $\begin{array}{l}6,13 \\
5,14 \\
6,17\end{array}$ & 5,87 & 0,003 \\
\hline D1- Usar o ensino a distância é prazeroso & $\begin{array}{l}\text { Concluído } \\
\text { Não Concluído } \\
\text { Em andamento }\end{array}$ & $\begin{array}{l}5,53 \\
4,64 \\
5,57 \\
\end{array}$ & 2,99 & 0,050 \\
\hline $\begin{array}{l}\text { CT2- Eu possuía os recursos, conhecimentos e } \\
\text { habilidades para usar o ensino a distância }\end{array}$ & $\begin{array}{l}\text { Concluído } \\
\text { Não Concluído } \\
\text { Em andamento }\end{array}$ & $\begin{array}{l}5,69 \\
5,71 \\
5,26\end{array}$ & 2,94 & 0,050 \\
\hline $\begin{array}{l}\text { CT3- Eu teria habilidade para usar bem o ensino a } \\
\text { distância nos meus processos de aprendizagem }\end{array}$ & $\begin{array}{l}\text { Concluído } \\
\text { Não Concluído } \\
\text { Em andamento }\end{array}$ & $\begin{array}{l}5,97 \\
5,50 \\
5,27 \\
\end{array}$ & 7,66 & 0,001 \\
\hline $\begin{array}{l}\text { CF1- Minha experiência em utilizar o sistema de } \\
\text { ensino a distância foi melhor do que eu esperava }\end{array}$ & $\begin{array}{l}\text { Concluído } \\
\text { Não Concluído } \\
\text { Em andamento }\end{array}$ & $\begin{array}{l}5,77 \\
4,85 \\
5,80 \\
\end{array}$ & 3,45 & 0,033 \\
\hline $\begin{array}{l}\text { S1- Estou satisfeito com o desempenho do ensino a } \\
\text { distância }\end{array}$ & $\begin{array}{l}\text { Concluído } \\
\text { Não Concluído } \\
\text { Em andamento }\end{array}$ & $\begin{array}{l}5,54 \\
4,35 \\
5,49\end{array}$ & 3,96 & 0,020 \\
\hline $\begin{array}{l}\text { S2- Estou satisfeito com a experiência de usar o } \\
\text { ensino a distância }\end{array}$ & $\begin{array}{l}\text { Concluído } \\
\text { Não Concluído } \\
\text { Em andamento }\end{array}$ & $\begin{array}{l}5,83 \\
4,64 \\
5,78\end{array}$ & 4,60 & 0,011 \\
\hline
\end{tabular}

As variáveis que apresentaram significância com a fase do curso foram: Percepção de utilidade: PU1 - usar o ensino a distância pode melhorar meu desempenho no aprendizado $(\mathrm{F}=3,696$, sig. $=0,026)$, na qual suas médias se apresentaram muito próximas: concluído $(5,90)$, não concluído $(5,07)$ e em andamento $(5,57)$. Com relação ao construto Atitude, temse as variáveis A1 - usar o ensino a distância é uma boa ideia $(\mathrm{F}=5,951$, sig=0,003), com as seguintes médias: concluído $(6,09)$, não concluído $(5,64)$ e em andamento $(6,29)$; A2 - eu gosto de usar o ensino a distância $(\mathrm{F}=5,87$, sig=0,003), com as seguintes médias: concluído 
$(6,13)$, não concluído $(5,14)$ e em andamento $(6,17)$. Ressalta-se que as médias das duas variáveis apresentaram um comportamento semelhante nas diferentes fases dos cursos.

Já no que se refere ao controle comportamental percebido, as variáveis que apresentam significância são: CT2 - eu possuía os recursos, conhecimentos e habilidade para usar o ensino a distância $(\mathrm{F}=2,94$, sig.= 0,050), apresentou médias próximas em valor: concluído $(5,69)$, não concluído $(5,71)$ e em andamento $(5,26)$. Para a variável CT3 - eu teria habilidade

para usar bem o ensino a distância nos meus processos de aprendizagem $(\mathrm{F}=7,66$, sig= 0,001), percebe-se que os alunos que já concluíram o curso apresentam maior média $(5,97)$, podendo afirmar que, por eles já terem concluído o curso, percebem que tem habilidade para usar o ensino a distância nos seus processos de aprendizagem, seguido dos que não concluíram $(5,50)$ e dos que ainda estão cursando $(5,27)$.

As variáveis a seguir apresentaram o mesmo comportamento com relação as suas médias, no que se refere aos alunos que não concluíram o curso, ou seja, os valores foram os mais baixos com relação as outras fases dos cursos: D1 - usar o ensino a distância é prazeroso $(\mathrm{F}=2,99$, sig. $=0,050)$, com média de 4,64; CF1 - minha experiência em utilizar o sistema de ensino a distância foi melhor do que eu esperava $(F=3,45$, sig. $=0,033)$, com média de 4,85 e, por fim, ao construto satisfação: S1- estou satisfeito com a experiência de usar o ensino a distância ( $\mathrm{F}=3,96$, sig. $=0,020)$, com média de 4,35 e S2 - estou satisfeito com a experiência de usar o ensino a distância ( $F=4,60$, sig=0,011), com média de 4,64. Constata-se, por este comportamento que os alunos que não concluíram o curso consideram o uso do ensino a distância menos prazeroso do que aqueles alunos que concluíram ou estão com o curso em andamento, bem como suas expectativas não foram superadas e estavam menos satisfeitos com o ensino a distância do que os outros respondentes.

Para sumarizar a influência do perfil na avaliação dos cursos PNAP, são identificados quais as características do perfil dos respondentes que mais são influenciadas pelas variáveis propostas pelo modelo. Num primeiro momento, destaca-se que não houve nenhum variável que foi mais afetada pelo perfil dos respondentes e que, em termos de dimensões, sobressaíram-se variáveis das dimensões controle percebido (CT) e confirmação das expectativas $(\mathrm{CF})$.

Conforme demonstra a Figura 4, a fase do curso em que o aluno estava, no momento da realização da pesquisa, foi a característica que mais gerou alterações nos atributos, gerando alterações em $32,14 \%$ dos itens propostos pelo modelo de mensuração; o curso que o aluno 
realizou influenciou em $25 \%$ das variáveis; a idade alterou $10,7 \%$ das variáveis; e o gênero não gerou nenhuma influência na avaliação dos cursos PNAP. Portanto, conclui-se que as variáveis que mais afetaram na percepção dos estudantes foram fase do curso ( 9 variáveis) e curso realizado (7 variáveis).

Supondo que cada uma das quatro características do perfil tivesse afetado todas as 28 variáveis, o perfil dos respondentes teria influenciado 112 variáveis (100\% dos itens), porém, ao total somente 19 foram influenciadas. Assim sendo, as características influenciaram apenas $16,96 \%$ das variáveis do modelo. Ou seja, o perfil do respondente apresenta pouca influência na avaliação e satisfação dos alunos com os cursos PNAP.

\begin{tabular}{|l|l|c|c|}
\hline \multicolumn{1}{|c|}{ Característica } & \multicolumn{1}{|c|}{ Variável com diferenças nas médias } & Total & Percentual \\
\hline Sexo & & 00 & $00,0 \%$ \\
Idade & CT1; CT2; CT3 & 03 & $10,70 \%$ \\
Curso & D1; NS1; NS2; CF1; CF3; PU3; S2 & 07 & $25,00 \%$ \\
Fase & PU1; A1; A2; D1; CT2; CT3; CF1; S1; S2 & 09 & $32,14 \%$ \\
\hline \multicolumn{2}{|c|}{$\mathbf{1 9}$} & & \\
\hline \multicolumn{1}{|c|}{$\mathbf{1 6 , 9 6 \%} \%$ Percentual } & \multicolumn{1}{|c|}{} \\
\hline
\end{tabular}

Figura 4 Resumo sobre as influências na avalição dos cursos PNAP

\section{CONCLUSÃO}

Após a realização deste estudo observou-se que o ensino a distância é uma realidade crescente no país e que tal processo parece ser irrevogável. Desta forma, cabe aos pesquisadores e profissionais da área buscar uma melhor compreensão do fenômeno e mecanismos de aperfeiçoamento para que a dimensão qualidade receba sua devida atenção.

Como primeiro objetivo, o artigo buscou identificar o perfil dos alunos do PNAP da IFES e os resultados apontaram que estes alunos encontram-se espalhados por todo o interior do estado do Rio Grande do Sul, a maior parte dos alunos é do sexo feminino $(60,6 \%)$, possuem idades que variam de 21 a 40 anos (74,5\%), possuem graduação em Administração $(39,8 \%)$ e são ou pretendem ser funcionários públicos $(78,39 \%)$.

Num segundo momento, indo ao encontro do objetivo de avaliar as percepções dos alunos, observou-se que as dimensões analisadas apresentaram boa classificação. Nesse sentido, a dimensão com pior avaliação foi norma subjetiva (média de 4,88) e a dimensão melhor avaliada foi atitude (média de 6,14). Isso demonstra que os alunos sofreram pouca 
influência de outras pessoas para se matricularam nos cursos PNAP e que possuem uma atitude positiva em relação ao curso, mesmo aqueles que abondaram seus respectivos cursos.

De forma semelhante a de outras pesquisas, o estudo também mostrou que o principal fator de evasão do ensino a distância foi o do não atingimento das expectativas, seguido da alegação de motivos pessoais e falta de tempo para realizar as tarefas e a falha na comunicação ou a demora na resposta de professores e tutores.

Por fim, respondendo ao terceiro objetivo do estudo, identificou-se que as influências do perfil dos respondentes na percepção da avaliação e satisfação com os cursos do PNAP foram poucas. O sexo não interferiu em nenhuma das variáveis do modelo de avaliação, a idade dos respondentes impactou em 3 variáveis, o curso que o alunos fazia impactou em 7 variáveis e a fase em que o aluno estava, impactando em 9 variáveis. Em suma, houve influência do perfil em $16,96 \%$ das variáveis, fato que leva a concluir que o perfil do respondente interfere muito pouco nas percepções dos alunos sobre os cursos PNAP.

Algumas das principais conclusões encontradas no estudo são: os alunos mais novos possuem maior controle sobre os processos necessários para a utilização do ensino a distância, ou seja, tem maior domínio dos recursos da plataforma moodle; o curso mais bem avaliado foi o de graduação em Administração Pública; os alunos que abandonaram o curso foram os que pior avaliaram seus respectivos, sendo que esse pode ser um dos fatores que levaram o discente a não concluir o curso PNAP.

Com relação às implicações desta pesquisa, no que tange as implicações acadêmicas, este trabalho buscou incrementar a discussão sobre os fatores que influenciam os alunos a aceitar o ensino a distância, visto que não há um padrão de variáveis que explique tal comportamento. Ou seja, o trabalho utiliza um modelo mais amplo, fugindo do tradicional Modelo de Aceitação de Tecnologia e incorporando a dimensão satisfação e confirmação das expectativas, que são muito importantes para que os cursos de ensino a distância continuem contribuindo com o ensino. Outra questão que merece reflexão é que, em relação à avaliação e satisfação dos cursos PNAP, o sexo não impactou em nenhuma variável, contrariando grande parte das pesquisas sobre comportamento humano e comportamento do consumidor que apontam o gênero como uma das principais variáveis intervenientes.

No que se refere às implicações para as instituições de ensino, principalmente para a IFES, duas dimensões merecem destaque: comprovação das expectativas e satisfação. Apesar das dimensões terem obtidos notas satisfatórias (em termo de 5,50), elas apontam uma 
avaliação positiva mediana e que carece de melhoria. Nesse sentido, as instituições que trabalham com o ensino a distância e, principalmente com os cursos do PNAP, precisam criar mecanismos para esclarecer a seus futuros alunos quais são as reais propostas do curso, destacando que ele é totalmente voltado para questões teóricas, com quase nenhum foco em aspectos práticos e ferramentas gerenciais. Este aspecto é necessário visto que os cursos PNAP são “cursos fechados”, com disciplinas e conteúdos padronizados, apostilas preparadas em nível nacional e com pouca flexibilidade em termos de conteúdo.

A pesquisa apresenta como limitações o fato de que o retorno dos questionários foi pequeno e, portanto, a amostra não foi estatisticamente significativa. Assim, sugere-se que este estudo seja reaplicado em outros cursos do PNAP, em amostras de diferentes perfis, em outros cursos ofertados pela UAB, bem como, na realidade de instituições privadas.

Apesar das limitações encontradas, acredita-se que, a partir dos resultados obtidos neste estudo, poderão surgir muitos outros problemas de pesquisa que se proponham a analisar a aceitação do ensino a distância pelos alunos, visto que um dos objetivos de um estudo acadêmico é ampliar o caminho para pesquisas futuras.

\section{REFERÊNCIAS BIBLIOGRÁFICAS}

ABBAD, G.; ZERBINI, T.; SOUZA, D. Panorama das pesquisas em educação a distância no Brasil. Estudos de Psicologia, v. 15, n. 3, p.291-298, 2010.

AJZEN, I. Attitudes, personality and behavior. Milton Keynes: Open University, 1988.

ALVES, R. R. A institucionalização dos cursos de administração pública a distância das universidades públicas: os casos UFLA e UFU. Dissertação (Mestrado em Gestão Estratégica, Marketing e Inovação)-Universidade Federal de Lavras, Lavras, 2012.

ANDRADE, A. F. A. Análise da evasão no curso de administração a distância: projetopiloto UAB: um enfoque sobre a gestão. Dissertação (Mestrado em Administração)Universidade de Brasília, Brasília, 2010.

BATTISTI, P.; CARDOSO, J. M. R.; MOREIRA, B. C. M.; KLAES, L. S.; DALMAU, M. B. L.; SAFANELLI, A. S. A interação tutor a distância e aluno no processo de ensino aprendizagem. Anais... X Coloquio Internacional sobre Gestión Universitária em América del Sur, Mar del Plata, 2010.

BRASIL. Decreto n. 2.454, de 10 de fevereiro de 1998: regulamenta o artigo 80 da LDB (Lei n. 9.894/96). Disponível em: <http:/www.mec.gov.br/legis/educdist.shtm>. 
BRUNO-FARIA, M. F.; FRANCO, A. L. Causas da evasão em curso de graduação a distância em Administração em uma Universidade Pública Federal. Teoria e Prática da Educação, v.14, n.3, p.43-56, 2011.

CASAGRANDE, L.; KLERING, L.; KRUEL, A. Estudo comparativo de percepções de alunos de Especialização Lato Sensu nas Modalidades Presencial e EAD. Anais...

EnANPAD, Rio de Janeiro, 2008.

CHEN, R.; HSIANG, C. A study on the critical success factors for corporations embarking on knowledge community-based e-learning. Information Sciences, v. 177, p. 570-586, 2007.

DAVIS, F. D. Perceived usefulness, perceived ease of use, and user acceptance of information technology. MIS Quarterly, v. 13, n. 3, p. 319-340, 1989.

DEMARCO, D. J. Um balanço do Programa Nacional de Formação em Administração Pública (PNAP) como estratégia de fortalecimento da Gestão Pública: o caso da UFRGS. Anais... VI Congresso CANSAD de Gestão Pública, Brasília, 2013.

GABBARD, R. B. Applying the technology acceptance model to online education.

Dissertation (Doctor of Philosophy). Indiana University, 2004.

GIAROLA, E.; NAZARETH, L.; NASCIMENTO, J.; JOAQUIM, N.; ANTONIALLI, L. Ambiente virtual de aprendizagem: um estudo sobre a satisfação de estudantes de Administração da UFL. Anais... II EnEPQ, Curitiba, 2009.

GOMES, E. F. Perfil e identidade do tutor em cursos na modalidade a distância do IFAL vinculados ao Sistema Universidade Aberta do Brasil: definições e prática docente. Revista Eletrônica Multidisciplinar Pindorama do Instituto Federal de Educação, Ciência e Tecnologia da Bahia - IFBA, n.1, ano.1, p.1-29, 2010.

HAIR, J. F. Jr.; ANDERSON, R. E.; TATHAM, R. L.; BLACK, W. C. Análise multivariada de dados. 6. ed. Porto Alegre: Bookman, 2009.

HARASIM L.; HILTZ S.; TELES, L.; TUROFF M. Learning networks: a field guide to teaching and learning on line. Cambridge: MIT Press, 1998.

ISHIDA, J. S.; STEFANO, S. R.; ANDRADE, S. M. Satisfação no ensino de pós-graduação à distância: a visão dos tutores e alunos do PNAP/UAB. Anais... XIV Semead- Seminários de Administração, São Paulo, 2011.

JUSTEN, C. E.; NETO, L. M.; FELIPPE, S. Reflexões sobre as práticas educativo-crítica, gestão social e educação a distância: o caso PNAP em Santa Catarina. Desenvolvimento em Questão, v.10. n.21, 2012.

LIU, S.; LIAO, H.; PRATT, J. Impact of media richness and flow on e-learning technology acceptance. Computers \& Education, v. 5, p. 599-607, 2009.

LIAW, S.; CHEN, G; HUANG, H. Users' attitudes toward web-based collaborative learning systems for knowledge management. Computers \& Education, v. 50, p. 950-961, 2008. 
MARTINS, L. L.; KELLERMANNS, F. W. A model of business school students acceptance of a web-based course management system. Academy of Management Learning and Education, v. 3, n. 1, p. 7-26, 2003.

MIKROPOULOS, T; NATSIS, A. Educational virtual environments: A ten-year review of empirical research. Computers \& Education, v. 56, 2011.

NETTO, C.; OLIVEIRA, A. R. M. Equidade e qualidade na educação superior no Brasil: o acesso por meio da educação a distância. Educação por Escrito, v.2, n. 1, 2011.

NISKIER, A. Educação a distância: a tecnologia da esperança. São Paulo: Loyola, 1999.

PARASURAMAN, A.; COLBY, C. Marketing para produtos inovadores: como e por que seus clientes adotam tecnologia. São Paulo: Bookman, 2002.

PILLA, B. Desenvolvimento de um sistema de avaliação de ensino a distância corporativo. Tese (Doutorado). Escola de Administração, Programa de Pós-Graduação em Administração, Universidade Federal do Rio Grande do Sul, Porto Alegre, 2007.

RISS, L. A; GROHMANN, M. Z. O uso da tecnologia no contexto educacional: análise de antecedentes da satisfação e da atitude de uso do ensino a distância. Anais... EnANPAD, Rio de Janeiro, 2012.

SCHOEDER, C.; KLERING, L. Ensino a distância como estratégia educacional e organizacional. Anais... EnADI, Florianópolis, 2007.

SILVA, L. M.; ANDRADE, A. F. A. Gestão do curso de administração pública a distancia da UEMA: enfoque nas funções da administração. Anais... ESUD 2013 - X Congresso Brasileiro de Ensino Superior a Distância, Belém, 2013.

SOUSA, A. S. Q. Universidade Aberta do Brasil (UAB) como política de formação de professores. Revista Educação em Questão, v.42, n.28. 2012.

TEIXEIRA, M. P. R.; SILVA, I. C.; OLIVEIRA, L. O. Ensino de Gestão Social: existe esta formação no curso EAD de Administração Pública da UAB? Anais... VI ENAPGS Encontro Nacional de Pesquisadores em Gestão Social, São Paulo, 2012.

TORRES, K. A.; BORBA, E. L.; MARTINS, P. L. A influência da atividade docente na qualidade dos cursos a distância. Anais... X ESUD -Congresso Brasileiro de Ensino Superior a Distância, Belém, 2013.

VENKATESH, V. User acceptance of information technology: toward a unified view. MIS Quarterly, v. 27, p. 425-478, 2003.

WEIDLE, D.; KICH, J. I. F.; PEREIRA, M. F. Projeto UAB: uma análise estrutural dos pólos de apoio presencial do curso de Administração da UFSC. GUAL- Gestão Universitária na América Latina. Edição Especial, p.94-114, 2011. 